\title{
Model Testing on Deformation Characteristics of an Unsaturated Compacted Clay Slope Under Cyclic Wetting and Drying
}

\author{
Yue HUANG ${ }^{\text {a }}$, Huiguo WU ${ }^{\text {b,c, } 1}$, Jian LIU ${ }^{\text {b,c }}$ and Yuedong $\mathrm{WU}^{\mathrm{b}, \mathrm{c}}$ \\ ${ }^{a}$ School of Civil Engineering, Xinjiang University, 1230 Yan'an Road, Tianshan \\ District, Xinjiang, China \\ ${ }^{\mathrm{b}}$ Key Laboratory of Ministry of Education for Geomechanics and Embankment \\ Engineering, Hohai University, No. 1, Xikang Road, Gulou District, Nanjing, China \\ ${ }^{\mathrm{c}}$ Geotechnical Engineering Research Center of Jiangsu Province, No. 1, Xikang Road, \\ Gulou District, Nanjing, China
}

\begin{abstract}
The effect of wetting-drying cycles on deformation characteristics of an unsaturated clay model slope is investigated in this study. The model slope was compacted using kaolin clay mixed with thirty percent of fine sand. The deformations of slope were measured using particle image velocimetry (PIV) technique. The test results revealed that the model slope deforms mainly within a depth of $300 \mathrm{~mm}$ and the displacements of soil mass are nearly perpendicular to slope surface in the first two cycles. Such displacements, however, vanish gradually in the subsequent cycles. On the other hand, the magnitude of displacement along slope surface increases with the number of wetting-drying cycles. The depth affected by wetting-drying cycles increases gradually with the number of wetting-drying cycles and becomes stable finally.
\end{abstract}

Keywords. Unsaturated clay, wetting-drying cycle, model slope, deformation

\section{Introduction}

Natural clay slopes are prone to deformation and damage after rainfall. Early field studies paid more attention to the impact of rainfall infiltration on slope stability, and believed that rainwater infiltration was one of the important factors to reduce slope stability [1-3]. However, a large number of studies have also found that many damaged slopes, even if it is assumed to be completely wetted, have an anti-skid safety factor much higher than 1 . This shows that the simple transition from unsaturated to saturated state is not the main reason for the failure of clay slopes. In recent years, scholars at home and abroad have carried out a series of studies on the deformation and stability of unsaturated clay slopes affected by dry and wet cycles. Take [4] used the mud static pressure method to make a kaolin slope model. In the centrifuge, the deformation law

\footnotetext{
1 Huiguo WU, Key Laboratory of Ministry of Education for Geomechanics and Embankment Engineering, Hohai University, No. 1, Xikang Road, Gulou District, Nanjing, China; E-mail: 18621069723@163.com.
} 
of the slope under the dry and wet cycle was studied, and it was found that the slope only swelled and deformed in the shallow layer during the wetting process. , And during the drying process, shrinkage and settlement deformation occurs in most areas of the slope, resulting in accumulated downslope-down deformation during multiple drying and wetting cycles. Lingwei K [5] conducted in-situ monitoring of expansive soil slopes in Nanning, Guangxi, and tracked and tested the evolution of slope deformation with climate. The study found that rainfall is the most direct external factor of expansive soil slope catastrophe. Evaporation effect is an important prerequisite for slope catastrophe; the slope produces horizontal deformation and settlement deformation simultaneously under the dry-wet cycle. The deformation is mainly concentrated in the surface soil, with the largest deformation in the slope, followed by the top of the slope, and the smallest deformation at the foot of the slope. Hudacsek [6] simulated the long-term deformation of over-consolidated moderately plastic compacted clay slopes under dry-wet cycles in centrifugation. The results showed that the slopes undergo both horizontal and vertical settlement deformations under dry-wet cycles. With the increase in the number of wet and dry cycles, the deformation of both gradually decreases, and eventually stabilizes, and the deformation mode of the whole process does not change. The above studies all show that the drywet cycle process is closely related to the long-term deformation and failure of the clay slope.

In order to reveal the law of deformation development of clay slopes under the action of dry and wet cycles, this article introduces the deformation test of clay slopes under the action of dry and wet cycles in a large indoor model tank, and analyzes the influence of the number of cycles of dry and wet on the deformation of clay slopes. The law of influence of characteristics.

\section{Slope Model Test Method}

The front size of the slope model box used in the test is shown in figure 1, and the model width is $500 \mathrm{~mm}$.

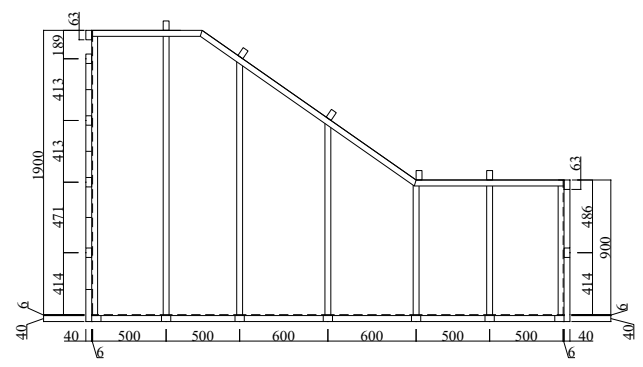

Figure 1. Dimensions of the model box (mm).

When making the model, the soil with a moisture content of $21 \%$ was used to make artificial slopes in the model box through the layered compaction method, with a compaction layer thickness of $50 \mathrm{~mm}$. The slope height of the slope model made is $870 \mathrm{~mm}$ and the slope is $33^{\circ}$. 
Compared with the mud static pressure method used by Take et al., the layered compaction method can form a certain internal structure and obtain a relatively high compaction dry density, which better reflects the over-consolidation phenomenon formed under the long-term action of natural slopes.

The soil material used in the model test is 3000 mesh washed kaolin, which is mixed with $30 \%$ fine sand to increase the permeability coefficient. The gradation of the test soil is shown in figure 2 , and its basic physical properties are shown in table 1.

Table 1. Physical indexes of the experimental soil.

\begin{tabular}{llllllll}
\hline $\begin{array}{l}\text { Type } \\
\text { of } \\
\text { soil }\end{array}$ & $\begin{array}{l}\text { Dry } \\
\text { density }\end{array}$ & $\begin{array}{l}\text { Liquid } \\
\text { limit }\end{array}$ & $\begin{array}{l}\text { Plastic } \\
\text { limit }\end{array}$ & $\begin{array}{l}\text { Saturated } \\
\text { permeability } \\
\text { coefficient }\end{array}$ & $\begin{array}{l}\text { Maximum } \\
\text { dry } \\
\text { density }\end{array}$ & $\begin{array}{l}\text { Optimal } \\
\text { water } \\
\text { content }\end{array}$ & $\begin{array}{l}\text { Particle } \\
\text { composition/\% }\end{array}$ \\
\hline & $/\left(\mathrm{g} / \mathrm{cm}^{3}\right)$ & $/ \%$ & $1 \%$ & $/(\mathrm{cm} / \mathrm{s})$ & $/\left(\mathrm{g} / \mathrm{cm}^{3}\right)$ & $/ \%$ & $\begin{array}{l}>0.075 \mathrm{~mm} \\
0.075 \mathrm{~mm}-0.005 \mathrm{~mm}\end{array}$ \\
$\begin{array}{l}\text { Silty } \\
\text { clay }\end{array}$ & 1.48 & 49.8 & 27.3 & $7.7 \times 10^{-7}$ & 1.50 & 24.0 & $\begin{array}{l}30.0 \\
49.0\end{array}$ \\
\hline
\end{tabular}

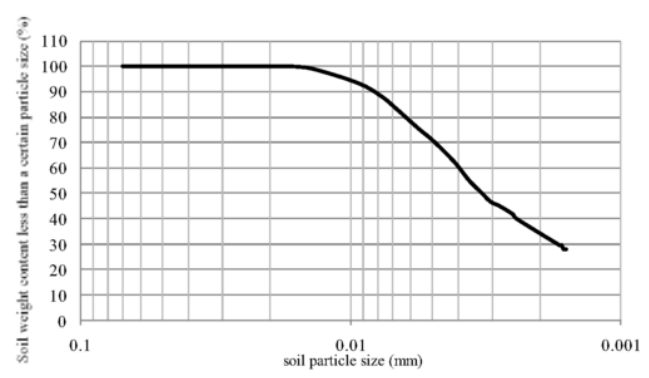

Figure 2. Gradation curve of test soil.

Considering that the model size is small and the water storage capacity of the slope soil is not strong, the rainfall and evaporation range used in the experiment are limited. In each dry-wet cycle, first apply $15 \mathrm{~mm} / \mathrm{h}$ rainfall to the slope for 5 hours, then dry, and evaporate freely on the slope for 48 hours. A total of 5 wet and dry cycles were performed.

The slope deformation measurement uses particle image velocimetry (PIV) technology [7]. During the preparation of the model slope, a small amount of coarse sand was used to make randomly distributed textures at the plexiglass observation window near the outside of the model box to facilitate image recognition. When using the PIV method to determine the displacement, the soil on the observation window of the model box is divided into several units. Since each unit has a unique arrangement of soil particles, the position change of the unit can be tracked according to the arrangement characteristics to determine the observation window Surface soil deformation. In this study, the GeoPIV program developed by White $[8,9]$ was used for identification and analysis. 


\section{Analysis and Discussion}

After the slope has undergone the circulation of evaporation and rainfall, it has undergone significant deformation. After the first dry-wet cycle, the deformation vector at each position of the slope model is shown in figure 3. After the rainfall and evaporation process, the compacted clay slope expands as a whole, and the slope top, slope surface and slope bottom all produce relatively uniform deformations perpendicular to the slope surface outwards. On the slope near the bottom of the slope, there is a small amount of displacement component that faces downward along the slope. The deformation of the slope at the slope surface is greater than that of the inside of the slope. At the same time, due to the low permeability coefficient of clay, it is difficult for evaporation and circulating water to enter the deep soil, so the deformed area is concentrated within $300 \mathrm{~mm}$ of the surface of the slope. At the same time, the depth of the deformed area is basically the same everywhere on the slope.

As the dry-wet cycle progresses, during each dry-wet cycle, the vertical outward deformation at each position of the slope gradually decreases, while the downward displacement component of the downslope continues to increase, and the slope deformation changes from being perpendicular to The upward swelling deformation of the slope gradually transforms into the downward sliding deformation of the slope. At the same time, the depth of the deformed area in the slope is deepening and finally reaches a relative stability.

By the fifth dry-wet cycle, the depth of the deformed area inside the slope will no longer deepen. The displacement vector distribution of each point of the slope is shown in figure 4. There is basically no deformation of the deep soil. The surface soil of the slope surface is all deformed downhill, and the depth of deformation at each position is basically the same. The displacement component of the bottom is increasing, and the slope deformation gradually transforms from the expansion deformation perpendicular to the slope upward into the downhill direction. The sliding deformation under the. At the same time, the depth of the deformed area in the slope is continuously deepened, and finally the phase deformation is basically equal, that is, the surface soil of the slope is moved as a whole. It is worth noting that when the slope surface is deformed along the slope, the slip surface is basically a straight line, which is similar to the sliding failure in non-cohesive soil slopes. At the same time, the phenomenon is also similar to that of natural clay slopes. Destroy the form. It can be inferred from this that the strength characteristics of the soil on the slippery surface may have changed after the dry-wet cycles, and the cohesive force existing at the time of the initial compaction of the clay may disappear.

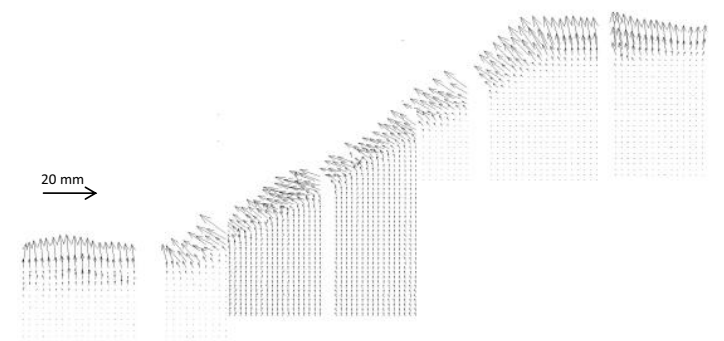

Figure 3. Deformation vector diagram of the slope under the first wetting-drying cycle. 


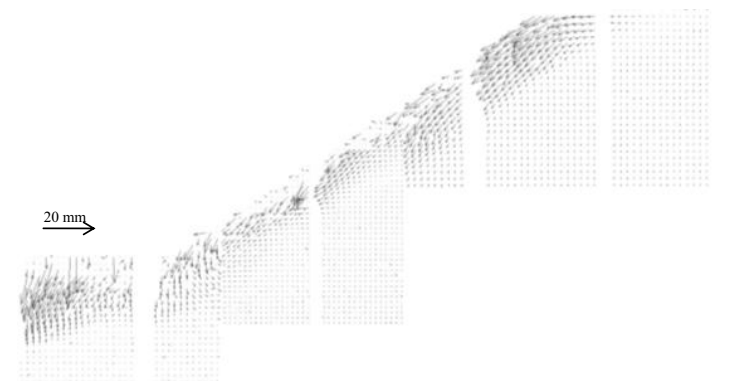

Figure 4. Deformation vector diagram of the slope under the fifth wetting-drying cycle.

For such a landslide failure form, the size of the slope height has no obvious effect. Therefore, the phenomenon disclosed in this test should also be applied to other sizes of soil slopes of similar materials.

The change process of the slope deformation range in the test is largely due to the low permeability of the soil. Different from the natural slope, the compacted soil slope prepared by the experiment has a uniform internal distribution in the initial situation and an extremely low permeability coefficient. On the one hand, under the action of rainfall, the initial permeability characteristics of all locations are the same. As the rainfall progresses, the soaked soil loses suction and expands and deforms, the permeability coefficient increases, and the soaking and expansion process gradually deepens. However, as the depth of soaking increases, the vertical stress of the soil gradually increases. Since the expansion deformation generally decreases with the increase of the stress, it is difficult to penetrate after the soaking and expansion reach a certain depth. On the other hand, as the evaporation progresses, the soil near the slope continuously loses water, and the permeability coefficient will also decrease. Under a certain evaporation intensity, the depth of the soil evaporation loss itself has a limit position. Under the combined action of the above two factors, the deformation range of the soil slope surface gradually changes and stabilizes during the cycle of rainfall and evaporation.

\section{Conclusion}

This paper studies the deformation law of the layered compacted clay slope under the action of dry and wet cycles, and the test finds that:

- The number of dry-wet cycles affects the deformation mode of unsaturated compacted clay slopes. With the increase of the number of dry-wet cycles, the deformation of the slope gradually changes from expansion deformation perpendicular to the slope surface upward to downward along the slope surface. Deformed along the slope, and eventually the expansion and deformation perpendicular to the slope completely disappeared.

- The depth of the slope deformation area under the dry-wet cycle increases with the increase in the number of cycles and eventually stabilizes, indicating that the depth of the impact of the dry-wet cycle on the unsaturated compacted clay slope is limited.

- After multiple cycles of drying and wetting, the surface deformation of compacted clay slopes becomes shallow, the surface of the slope moves along 
the slope, and the sliding surface of the deformed body is straight, similar to the slippage in non-cohesive soil slopes. damage.

\section{References}

[1] Hu QG, Yuan N, Liu DS, He ZM. Rainfall infiltration process and stability analysis of soil slope with multi-layer structure. China Journal of Highway and Transport. 2018 Feb; 31(2): 67-74.

[2] Chen LS, Wei BX, Liao H, Zhang HB. Coupling analysis of unsaturated seepage and progressive failure of expansive soil slopes. Hydrogeology and Engineering Geology. 2020 Jul; 47(4): 132-140.

[3] Liang S, Xie Q, Guo YC, Ye TG. Centrifugal test of expansive soil foundation pit slope under rainfall infiltration conditions. Geological Science and Technology Information. 2019 Mar; 38(2): 249-255.

[4] Take WA, Bolton MD. Seasonal ratcheting and softening in clay slopes. Geotechnique. 2011 Sept; 61(9): 757-769.

[5] Kong LW, Chen JB, Guo AG, Zhao YL, LV HB. Field response tests on expansive soil slopes under atmosphere. Chinese Journal of Geotechnical Engineering. 2007 Jul; 29(7): 1065-1073.

[6] Hudacsek P, Bransby MF, Hallett PD. Centrifuge modelling of climatic effects on clay embankments. Engineering Sustainability. 2009 Jun; 162(2): 91-100.

[7] Keane RD, Adrian RJ. Theory of cross-correlation analysis of PIV images. Applied Scientific Research. 1992 Jul; 49(3): 191-215.

[8] Take WA, Bolton MD, Wong P, Yeung FJ. Evaluation of landslide triggering mechanisms in model fill slopes. Landslides. 2004 Sept; 1(3): 173-184.

[9] White DJ, Take WA, Bolton MD. Soil deformation measurement using particle image velocimetry (PIV) and photogrammetry. Geotechnique. 2003 Apr; 53(7): 619-631. 